\title{
A thermophysical study of the melting process in alkyl chain metal n-alkanoates: The thallium (I) series
}

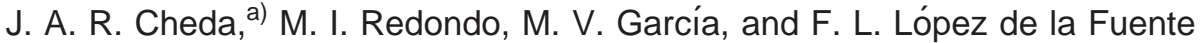 \\ Dpto. Química-Física I, Fctd. CC. Químicas, Universtitaria Complutense, 28040 Madrid, Spain \\ F. Fernández-Martín \\ Instituto del Frío (CSIC), Ciudad Universitaria, 28040 Madrid, Spain \\ E. F. Westrum, Jr. \\ Department of Chemistry, University of Michigan, Ann Arbor, Michigan 48109-1055
}

(Received 20 October 1998; accepted 1 June 1999)

\begin{abstract}
The peculiar thermal behavior of the thallium(I) $n$-alkanoates series (consisting in several transitions between polymorphic and mesomorphic phases) in comparison with other metallic $n$-alkanoates series is stated. The allowance of highly accurate adiabatic heat capacity data permits a study of the $\mathrm{CH}_{2}$ contributions to the lattice heat capacity curve at low temperature. Moreover, in this series an anomalous gradual enhancement of the lattice heat capacity has been interpreted from vibrational spectroscopy results as a noncooperative effect due to the internal hindered rotation of the alkyl chain (formation of gauche defects, even in the solid state). The thermodynamics of the "stepwise melting process" from the totally ordered solid at low temperature to the isotropic liquid is based on a revised lattice heat-capacity curve. This was used to evaluate the energy and entropy not only of the clear first order transitions present in the series but also of the described noncooperative effect. The $\mathrm{CH}_{2}$ enthalpy and entropy contribution for this series is estimated and a comparison with the published values for other series is carried out. Moreover, the texture of the mesophases is revealed by polarized light microscopy. (c) 1999 American Institute of Physics.

[S0021-9606(99)51132-X]
\end{abstract}

\section{INTRODUCTION}

The ionic mesomorphism shown by most "organic" salts (i.e., salts with an organic ion and an inorganic counterion) is one of the most interesting aspects of these materials. More than three decades ago, when these salts began to become of general interest, it was observed ${ }^{1}$ that the ease with which the cationic (or anionic) radius and the detailed configurations of the cation (or anion) varied at will provides a unique brand to model ionic liquid crystals, potentially suitable for very diverse scientific and technological applications. Ionic liquid crystals are used as an anisotropic medium for the synthesis of either organic or inorganic materials, or as a fluid matrix for various spectroscopic purposes. In addition they also exhibit a greatly enhanced optical sensitivity even to weak electric fields (compared to classic smectic phases). ${ }^{2}$ Indeed, in the exploitation of their amphiphylic character which produces surfactant behavior in either polar or nonpolar solvents they are potentially very powerful adjuncts to the creative investigator. But other aspects of interest may also be cited. Their lamellar crystal structures with layers of parallel chains alternating with other ionic layers makes them appropriate-as pure anhydrous salts-in modeling phospholipid biological membranes. ${ }^{3,4}$

Thallium(I) $n$-alkanoate series (hereafter $\mathrm{T} \ln \mathrm{C}$, where $3 \leqslant n \leqslant 14$ ) have been studied by us $^{5-18}$ over more than a

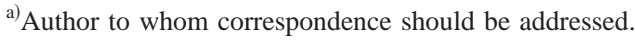

Electronic mail: cheda@eucmos.sim.ucm.es
}

decade. This study comprizes both their thermal and structural properties. This series proves to be one of the most interesting within the organic salts in general, because it presents much more polymorphism than do other analogous series (i.e., some alkaline salt series). In all the members of the series studied, several solid-state polymorphs were found apart from the ionic thermotropic mesomorphism which appears when the number of carbon atoms $n \geqslant 5$.

In addition, the results from FTIR and Raman spectroscopy ${ }^{5}$ showed that a noncooperative phenomenon embracing internal rotations as well as van der Waals forces along chains must be considered in the study of the "chain melting" process. This process involves the transformation of the ordered solid near zero Kelvin (with all the methylene groups of the alkyl chain in all-trans position) to the hightemperature isotropic liquid. The vibrational spectroscopic data also suggest that the high-temperature solid phases must be considered as "condis" phases (conformational disordered phases) following the classification proposed by Wunderlich. ${ }^{19}$

In our first determination of enthalpy and entropy functions of the solid-to-solid transitions, the existence of these noncooperative phenomena (observed as a gradual enhancement of the heat capacity curves determined by dsc and adiabatic calorimetry) was not clearly understood, and their contribution to the total transition thermodynamic functions was not taken into account. This makes necessary a revision of our earlier determined values of total enthalpy and entropy 
associated to this stepwise melting process from the ordered crystal at low $T$ to the isotropic liquid.

Lindau et al $^{20,21}$ have also published data on transitions above room temperature for several compounds of this series but they did not report any heat capacity data. It is also worthy of mention the Krombach and Schneider ${ }^{22}$ work on the pressure versus temperature phase diagram of thallium(I) $n$-tetradecanoate showing the disappearance of solid I phase at high pressure and the formation of a solid II-solid I-liquid crystal triple point.

This paper is concerned with reviewing the thermophysical aspects associated with the many transitions throughout the thallium(I) series $[3<n<14]$ and the influence of the methylene groups on them. Moreover, the methylene contribution to the lattice heat capacity has also been studied and compared with that of other homologous series and with the statistically calculated contribution per $\mathrm{CH}_{2}$ group of the alkyl chain.

\section{RESULTS AND DISCUSSION}

The most relevant points emerging from the dsc and adiabatic calorimetry study of the series under discussion are indicated as follows:

\section{A. Recognition of the importance of the anomalous gradual enhancement in the heat-capacity curve}

When representing heat-capacity values both by adiabatic (ac) and differential scanning (dsc) calorimetries for each member of the thallium series $(\operatorname{Tl} n \mathrm{C}, n$ $=3,4,5,6,7,8,10,12,14)^{6-18}$ from the liquid helium region the complete morphology of the heat capacity versus $T$ is obtained (cf. Fig. 1). Independently of the clearly first order polymorphic, fusion, or "clearing" transitions, an anomalous enhancement in the lattice heat capacity is observed over a very broad interval of temperature (150-200 K), which is represented in Fig. 1 by a cross-hatched area for some compounds. This anomalous gradual enhancement was observed in all members of the thallium series (beyond $n$ $=5$ ) measured by adiabatic calorimetry, and its maximum appears in the heat-capacity curve (as in $\mathrm{T} 112 \mathrm{C})^{10}$ or hidden beneath a first order transition (as in T110C). ${ }^{11}$

The gradual enhancement is seen more clearly by adiabatic calorimetry. It is inherent in the nature of dsc that in obtaining a measure of the enthalpy of transition, $\Delta_{\text {trs }} H$, of a major transition a relatively insensitive scale for the instrumental graphical presentation is selected that permits evaluation of the apparent $\Delta_{\text {trs }} H$ but obliterates the details of the lattice contribution and hence tends to minimize the $\Delta_{\text {trs }} H$. In the adiabatic calorimetry technique the resolution of the lattice heat capacity does involve some arbitrary aspects, but here the measured actual total enthalpy $\Delta_{\text {tot }} H$ is not in question, only the resolution of the total thereof into the lattice enthalpy $\left(\Delta_{\text {lat }} H\right.$ ) and the excess $\Delta H^{x s}$ (or indeed $\Delta_{\text {trs }} H$ ) contribution. It is easy to err in the direction of minimizing $\Delta H^{x s}$. Hence in evaluating $\Sigma_{i}\left(\Delta_{\mathrm{trr}} H\right)_{i}$-or the corresponding entropy summation - we readily attributed a low value to the excess contribution to the total enthalpy-or entropy. Therefore, an adjustment has been made to previously pub-

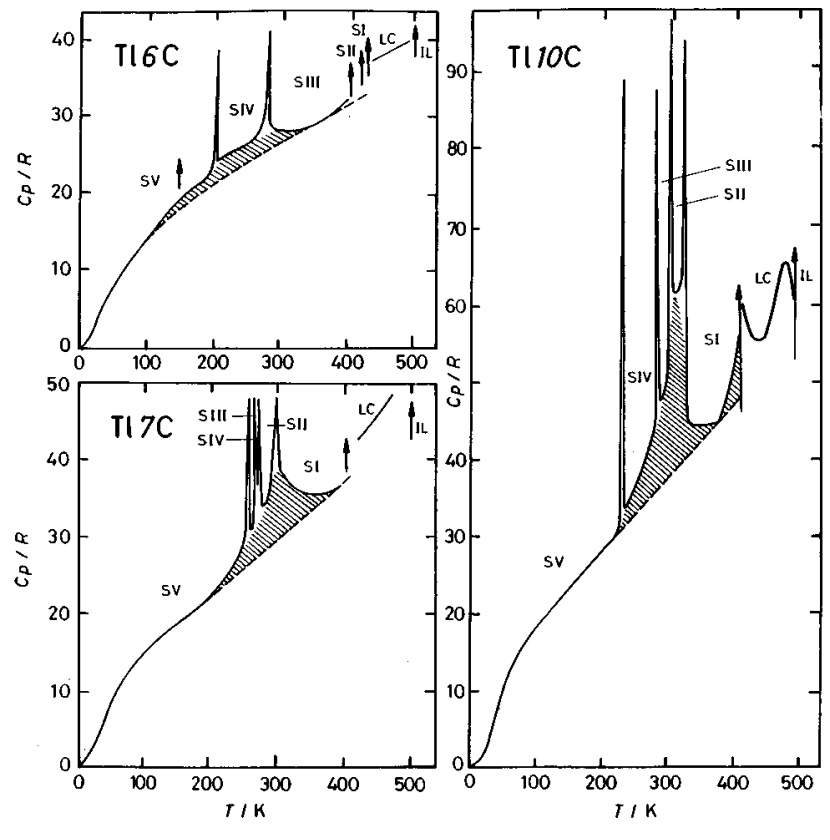

FIG. 1. Molar heat capacity versus temperature of the specified thallium(I) $n$-alkanoates. Arrows represent phase transition temperatures. IL $=$ isotropic liquid; $\mathrm{M}=$ mesophase; Roman numerals=different crystalline phases. Shaded areas show the enhancement in the heat capacity morphology. [From García et al. (Ref. 5), with permission.]

lished $\Delta_{\text {trs }} H$ and $\Delta_{\text {trs }} S$ values. In Fig. 2, the enthalpy and entropy "overlooked" areas for T110C and how they arose are shown. The dashed lines represent the original ${ }^{6-18}$ arbitrary extrapolations selected for the lattice heat capacity trends whereas the dot-dashed lines represent a selection of the lattice curves obtained by extrapolation of an exponential function adjusted to the experimental heat-capacity data at very low temperature. The cross-hatched areas between them represent the estimated enthalpy and entropy associated to the gradual enhancement of the heat capacity that should be included as a term in the total enthalpy and entropy of the global melting process (see Sec. IIE). Only by taking this term into account accordance between theoretical and experimental results can be obtained, as it will be explained later (cf. Table I).

The lattice heat-capacity curves were evaluated for each compound in this work fitting an exponential function of the type: $C_{p}=A+B \cdot T^{C}$ to the experimental heat-capacity data at low temperature. In this adjustment all the experimental data from the inflection point of the $C p$ vs $T$ curve up to the beginning of the pretransitional effects were taken into account. The results obtained for all the compounds measured by adiabatic calorimetry are shown in Fig. 3 .

\section{B. Methylene contribution to the lattice heat capacity}

Many articles have been published on the thermal properties of the methylene group related to its lattice heatcapacity contribution. They are based always on the measurements taken on several consecutive members of homologous series with hydrocarbon chains in their structure. ${ }^{23-29}$ The availability of highly accurate data of the molar heat capacity from very low temperatures for several 


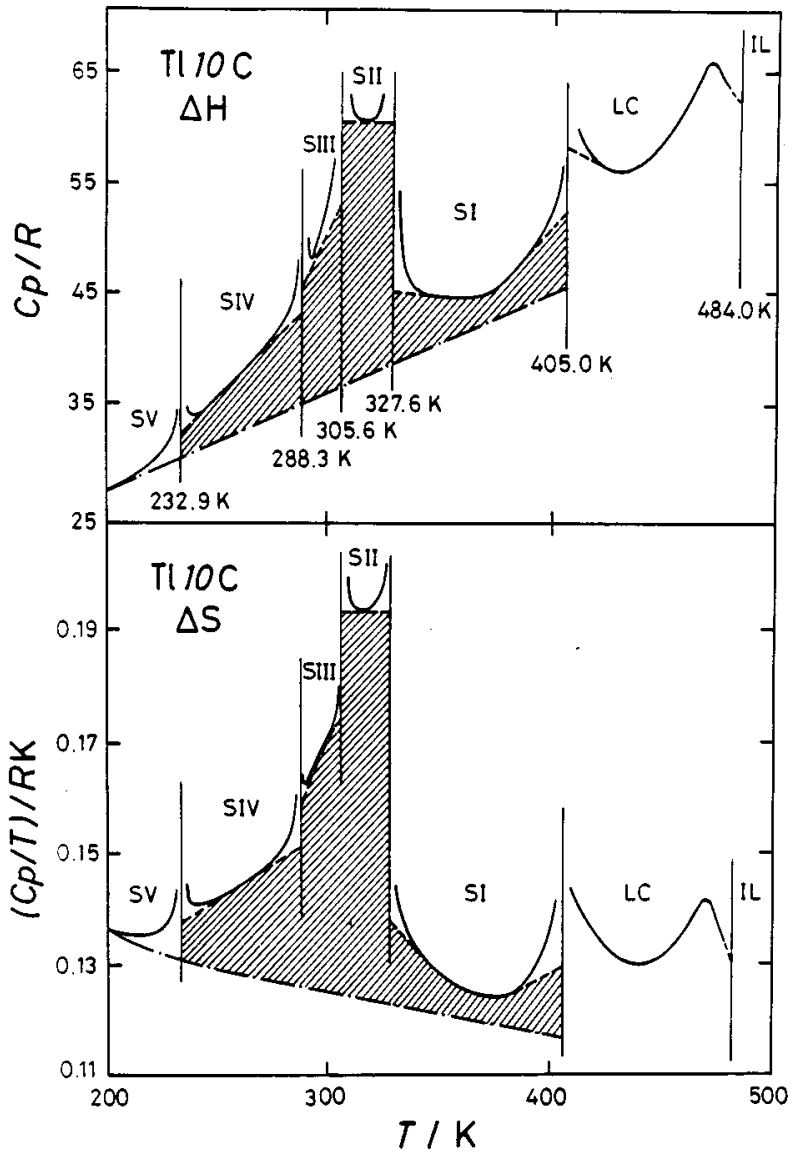

FIG. 2. Examples of the enthalpy and entropy calculations (crossed-hatched areas) associated to the gradual enhancement of the heat capacity. Dashed lines represent the original arbitrary extrapolations used as the lattice heatcapacity curves in Refs. 6-18. The dot-dashed lines represent the selected extrapolated curves obtained by the adjustment of the experimental heatcapacity data at very low temperature to an exponential function (see text).

members of the thallium(I) $n$-alkanoate series have allowed us to undergo a very precise calculation of the $\mathrm{CH}_{2}$ contribution to the lattice heat capacity. These calculations are necessarily limited to the low temperature range below the temperatures of transitions in the crystalline phase because such transitions are macroscopic evidence of more compli-

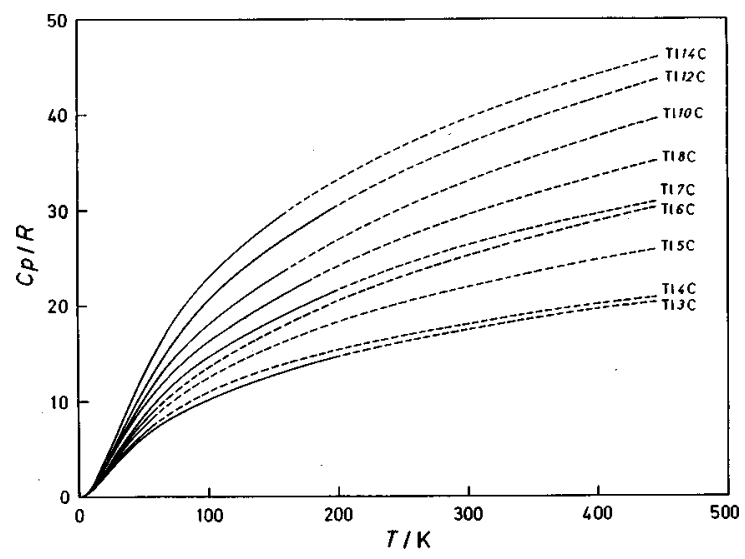

FIG. 3. Experimental heat-capacity values (full lines) superimposed on the fitted extrapolated heat capacities (dotted lines).

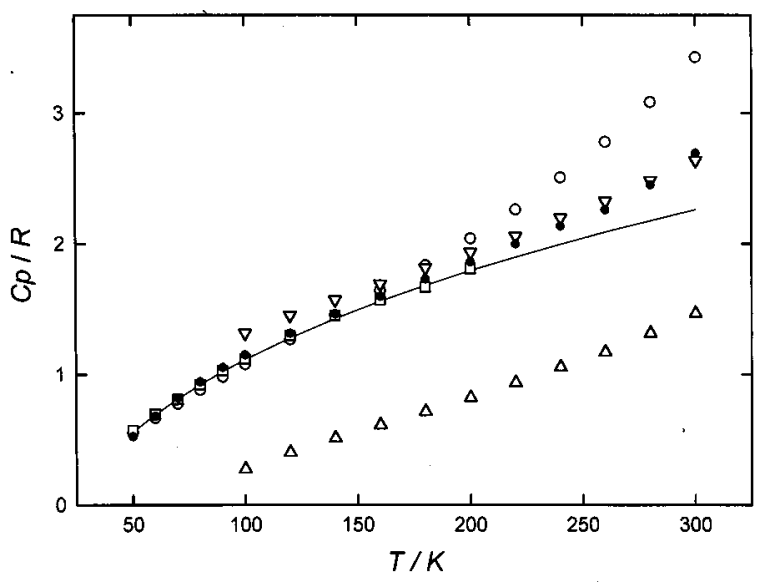

FIG. 4. $\mathrm{CH}_{2}$ contribution to the lattice heat capacity. $\square$, thallium(I) $n$-alkanoates (this work); $\triangle, n$-alkanes without hindered rotation term (Ref. 23); $\nabla, n$-alkanes with hindered rotation term (Ref. 23); $\bigcirc$, bilayeredperovskites (Ref. 27); $\bullet$, paraffins (Ref. 29).

cated interactions among the chains. Jin and Wunderlich ${ }^{29}$ in their model to evaluate thermal properties of paraffins and polyethylene found an odd/even effect for the $\mathrm{CH}_{2}$ contribution to the lattice heat capacity. Since we have only data for the three shortest odd members we cannot discuss the existence of this effect in thallium series. The experimental values ${ }^{6-18}$ used in the evaluation of the $\mathrm{CH}_{2}$ contribution are shown in Fig. 3 as a bold line. Consequently, we have determined the variation of the $\mathrm{CH}_{2}$ heat capacity at each particular temperature as

$$
C_{p, m}\left(\mathrm{CH}_{2}\right)=\left[C_{p, m}(\mathrm{Tl} n \mathrm{C})-C_{p, m}(\mathrm{Tl} k \mathrm{C})\right] /(n-k)
$$

using all the possible binary combinations of all the compounds measured by adiabatic calorimetry $(n, k$ $=3,4,5,6,7,8,10,12,14)$. This method eliminates all the contribution to heat capacity but those due to the $\mathrm{CH}_{2}$ group. The results are represented in Fig. 4, together with other data obtained by a similar method by White $^{27}$ for bilayeredperovskites with the formula $\left(\mathrm{C}_{n} \mathrm{H}_{2 n+1} \mathrm{NH}_{3}\right)_{2} \mathrm{MX}_{4}$ $(\mathrm{M}=$ metal, $\mathrm{X}=$ Halogen), the calculated by Pearson and Pimentel, ${ }^{23}$ and those evaluated by Jin and Wunderlich ${ }^{29}$ for $n$-alkanes.

The derived equation for the heat capacity of the $\mathrm{CH}_{2}$ contribution in the series under study is:

$$
C_{p, m}\left(\mathrm{CH}_{2}\right)=\left(-1.92+0.79 T^{0.29}\right) R
$$

for the interval of temperature of $50-300 \mathrm{~K}$, and is represented as a continuous line in Fig. 4.

Due to the intrinsic interest of the dynamics of the $\mathrm{CH}_{2}$ unit, we have made a semiquantitative attempt of comparison between our experimental results and those obtained by a very simple model developed first by Pitzer $^{30}$ and later improved by Person and Pimentel ${ }^{23}$ and by Janz. ${ }^{31}$ Despite its simplicity, this model explains many features of the heatcapacity curve and indicates that the contributions to the heat capacity are additive including terms for each degree of freedom associated with the following vibrational modes: $\mathrm{C}-\mathrm{C}$ stretching, $\mathrm{C}-\mathrm{C}$ bending, the six modes of the $\mathrm{CH}_{2}$ group (symmetric and asymmetric stretching, bending, rocking, wagging, and twisting), and a final term due to hindered 


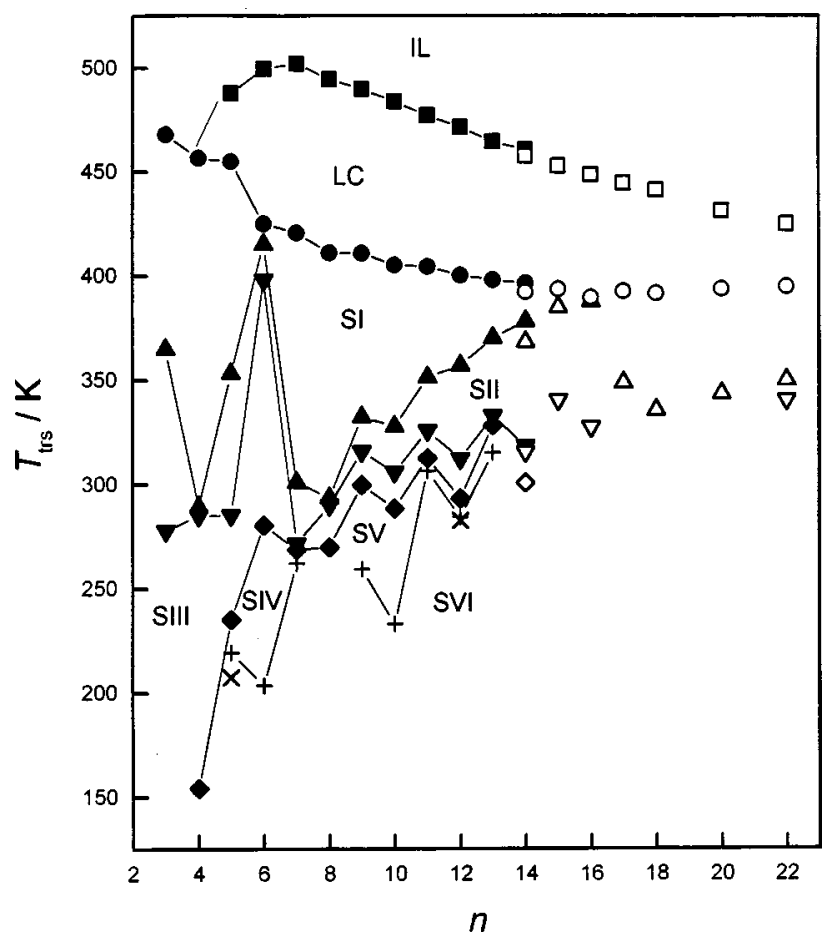

FIG. 5. Temperatures of transition between phases of the thallium(I) $n$-alkanoates and the total number of carbon atoms $n$ in the chains. SI, SII, etc. designate solid phases; LC, liquid crystal; and IL, isotropic liquid. Symbols: $\mathbf{~ c l e a r i n g ; ~} \bullet$ fusion; $\boldsymbol{\Lambda}, \boldsymbol{\nabla}, \downarrow,+, \times$, solid-to-solid transitions. Open symbols, data from Refs. 20, 21.

rotation. The first contributions were calculated using the Einstein functions with the proposed frequencies ${ }^{23}$ and are represented by triangles in Fig. 4. The value of the hindered rotation term depends on the barrier of potential chosen. In this figure the inverted triangles represent the Person and Pimentel $^{23}$ calculations for $n$-alkanes assuming a value for the frequency of the torsional oscillation consistent with the $n$-alkane experimental values. The $\mathrm{CH}_{2}$ heat-capacity values (average of the odd and even members values) in Ref. 29 represented by solid circles are in good agreement with our reported data until $200 \mathrm{~K}$, but are higher and the differences increase above this temperature as do the Pearson and Pimentel's ones in the whole range (hindered rotation considered). Hence we conclude that the internal rotation in this series is less hindered than for $n$-alkanes, as would be expected, in view of the large size of the head group in thallium series $\left(-\mathrm{COO}^{-} \mathrm{Tl}^{+}\right)$in comparison with that of paraffins $\left(-\mathrm{CH}_{3}\right)$.

Above $200 \mathrm{~K}$ the reported values for perovskites ${ }^{27}$ seem to be overestimated probably due to pretransitional effects above $200 \mathrm{~K}$ of the member $\left(n-\mathrm{C}_{18} \mathrm{H}_{37} \mathrm{NH}_{3}\right)_{2} \mathrm{CdCl}_{4}$ used to evaluate the $\mathrm{CH}_{2}$ heat capacity in this series.

\section{Phase behavior as a function of chain length}

The complex of phase behavior in members of the thallium(I) $n$-alkanoates can be regarded in the Fig. 5 overview. In summary:

- From T15C through T114C all compounds studied have

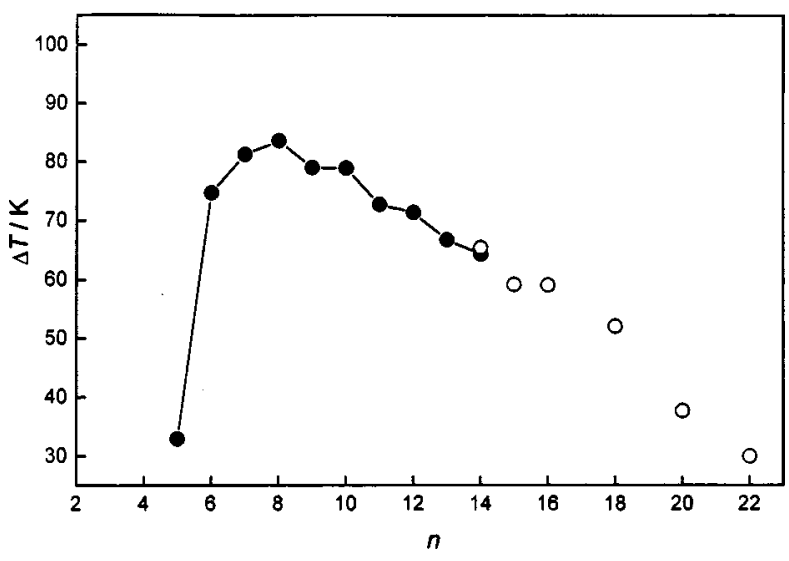

FIG. 6. Mesophase stability $\Delta T / \mathrm{K}$ range of thallium(I) $n$-alkanoates as function of total number of carbon atoms, $n$. Solid symbols: this work; open: data from Ref. 20.

an anisotropic liquid mesophase characterized by polarized light microscopy as Smectic-A-type (designated "neat") phase (cf. the Appendix).

- The $T_{\text {trs }}$ for crystalline transitions show a clearly alternating even/odd sequence characteristic of many other homologous series. This phenomenon is less apparent in fusion temperatures, $T_{\text {fus }}$, and even less in those of "clearing," $T_{\text {clr }}$. The same behavior was observed by Lindau et al. ${ }^{20,21}$ for transitions taking place in $\mathrm{Tl} n \mathrm{C}$ $(n=2-22)$ above room temperature. The transition temperatures measured by these authors agree with our values within the experimental error with the only exception of a transition at $309.7 \mathrm{~K}$ for the $\mathrm{Tl} 14 \mathrm{C}$, not seen neither by us nor by Krombach et al. ${ }^{22}$ For this reason and in order to be clear enough only data for members with $n \geqslant 14$ from these authors are included in Fig. 5.

- The stability range of the mesophase, $\Delta T_{\text {meso }}$, measured throughout the temperature interval of its existence between clearing and fusion $\left(\Delta T_{\text {meso }}=T_{\text {clr }}\right.$ $-T_{\text {fus }}$ ) increases with $n$ (the number of carbon atoms in the chain) to a maximum at $n=8\left(\Delta T_{\text {meso }}=83.7 \mathrm{~K}\right)$, and decreases monotonically with additional increase in chain length (cf. Fig. 6 where data from Refs. 20, 21 are also shown). It can be estimated by extrapolation of all the available data that the mesophase should disappear for members with $n \geqslant(25-30)$.

- The decrease in the stability range of the solid I phase for compounds with $n>8$ points to its disappearance at $n$ higher than those studied in this work. According to Ref. 21 this may happen at $n=17$. The evolution of $T_{\text {trs }}$ vs $n$ suggests that solid phases correspond to each other only for $n \geqslant 7$. This is in agreement with the FTIR studies, ${ }^{5}$ which show that band splittings observed at low temperatures disappear at the SIII-to-SII transition temperature for members with $n \geqslant 7$.

\section{Enthalpy and entropy increments of transition}

Figure 7 shows the variation of enthalpy, $\Delta_{\text {cry }}^{\text {liq }} H$, vs $n$. This variation implies a summation over excess contributions from near $0 \mathrm{~K}$ to the isotropic liquid just above the clearing temperature: 


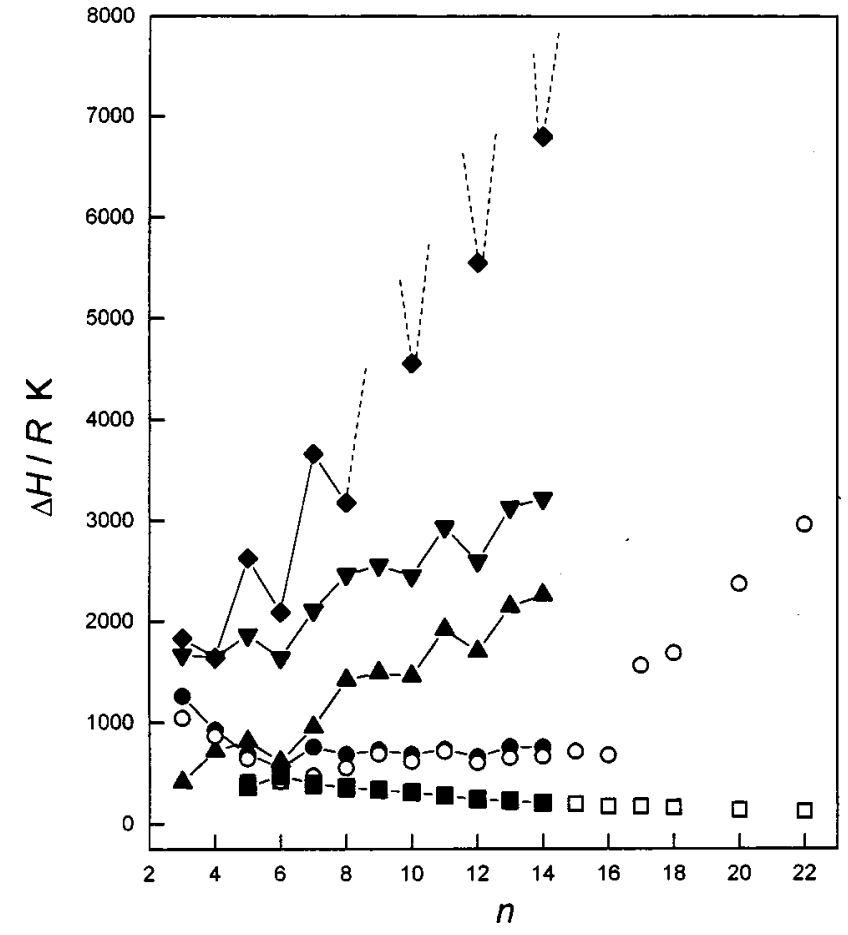

FIG. 7. Enthalpy of the observed transitions for thallium(I) $n$-alkanoates vs number of carbon atoms, $n$. Open symbols, data from Refs. 20, 21. $=\Delta_{\text {cry }}^{\text {lig }} H, \boldsymbol{\Delta}=\Sigma_{i} \Delta_{S S} H_{i}, \boldsymbol{O}=\Delta_{\text {fus }} H$, and $\boldsymbol{\square}=\Delta_{\mathrm{clr}} H, \boldsymbol{\nabla}=\Sigma_{i} \Delta_{S S} H_{i}+\Delta_{\text {fus }} H$ $+\Delta_{\mathrm{clr}} H$.

The summation includes experimental values (also included in Fig. 7) of:

- $\Sigma_{i} \Delta_{s s} H_{i}$ for crystal to crystal transitions, as published in Refs. 6-18.

- $\Delta_{\text {fus }} H$ for fusion (melting to a mesophase if it exists)

- $\Delta_{\mathrm{clr}} H$ for clearing from the mesophase to the isotropic liquid.

- $\Delta_{\text {grd enh }} H$ for the gradual enhancement of heat capacity already described (see paragraph 2).

Then, it can be written:

$$
\Delta_{\text {cry }}^{\text {liq }} H=\sum_{i} \Delta_{S S} H_{i}+\Delta_{\text {fus }} H+\Delta_{\text {clr }} H+\Delta_{\text {grd enh }} H .
$$

The $\Sigma_{i} \Delta_{S S} H_{i}$ contribution increases with the number of carbons and could be associated with structural changes depending on the chain length. $\Delta_{\text {fus }} H(\sim 700 R \mathrm{~K})$ is a value practically independent of the hydrocarbon chain length for compounds of the series having mesophases $(n \geqslant 5)$. Data for $\Delta_{\text {fus }} H$ from Refs. 20 and 21 confirm the same pattern for the series members with $n \leqslant 16$. From $n=17$ phase I disappears and the enthalpy increment for the SII-to-SI transition is added to the $\Delta_{\text {fus }} H$ which increases up to $1563 R \mathrm{~K}$ for this member. For higher $n$ members this function increases with the chain length. For Tl3C and T14C, $\Delta_{\text {fus }} H$ has a noticeable contribution to the $\Delta_{\text {cry }}^{\text {liq }} H$. From these facts, two conclusions follow: first, the crystal I and mesophases of members of the series up to $n=16$ are similar and isostructural (with the possible exception of the two compounds mentioned above); and second, the fusion processes in these short chain mem- bers is associated with electrostatic ionic interactions. In the shortest chain compounds $(n=3,4)$, these interactions are dominant, and are the main contribution to the global enthalpy increment corresponding to the fusion process. For the longer chain compounds, the results are more dependent on the intra- and inter-molecular interactions of the hydrocarbon chains.

The "clearing'" transition enthalpy varies between $200 R$ and $500 R \mathrm{~K}$ for the compounds studied, small but consistent value for the passage from a Smectic $\mathrm{A}$ in the liquid mesophase to the isotropic liquid. Moreover, $\Delta_{\mathrm{clr}} H$ decreases practically linearly with increasing $n$ tending toward zero for $n$ between 25 and 30. Likewise, the same value for $n$ is obtained by extrapolation of the temperature interval of stability of the mesophase versus $n$. Hence, one can infer, on one hand, the disappearance of the mesophase for thallium(I) $n$-alkanoates with 25-30 carbon atoms and, on the other, the small influence of the alkyl chain fusion on the clearing process. The same conclusion can be attained from the results of Refs. 20,21 (see Fig. 7).

With the exception of $\Delta_{\text {clr }} H$ noticeable odd/even effects are found which are due to differences of enthalpy increments between phases of adjacent members of the series. This effect was also observed by Lindau et al. ${ }^{20,21}$ for the transition observed by them for members with $n \geqslant 9$. In the following discussion Lindau et al. data are not considered because they did not measure any transition below $300 \mathrm{~K}$. Moreover, as they did not measure heat capacities, no evaluation of the "gradual enhancement of the lattice heat capacity" could be done. Although the members with $n=9,11$, and 13 were not measured by adiabatic calorimetry in our work and consequently $\Delta_{\text {grd enh }} H$ could not be evaluated for these compounds, it is clear that for odd members, $\Delta_{\text {cry }}^{\text {liq }} H$ values are higher than those for the adjacent even members. Adjusting these experimental values for the even members to a straight line, a slope of $(515 \pm 27) R \cdot K$ is obtained. This value is associated with the methylene unit contribution to the fusion of the aliphatic chains from the completely ordered crystalline state up to the isotropic liquid, ${ }^{25,26}$ and is in agreement with the corresponding value for other analogous series (see Table I). ${ }^{32-46}$ Taking into account only the terms $\Sigma_{i} \Delta_{S S} H_{i}, \Delta_{\text {fus }} H$, and $\Delta_{\text {clr }} H$ for thallium(I) $n$-alkanoate series, the enthalpy increment per methylene unit is only (160180) $R \cdot K, 40 \%$ less than the average value found for homologous series. It is clear that the $\Delta_{\text {grd enh }} H$ term should be included in the calculation of $\Delta_{\text {cry }}^{\text {liq }} H$ because it is related to the "fusion" (increase of the conformational disorder) of the alkyl chain, as observed in our FTIR study. ${ }^{5}$

A similar study can be developed for the entropy associated with the stepwise melting. Similar to Eq. (3) it can be written:

$$
\Delta_{\text {cry }}^{\operatorname{liq}} S=\sum_{i} \Delta_{S S} S_{i}+\Delta_{\text {fus }} S+\Delta_{\text {clr }} S+\Delta_{\text {grd enh }} S .
$$

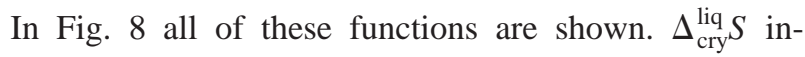
creases with the chain length. Such an increase in entropy may be achieved either by increases in entropy through excitation of already existing transitions in the short chain homologues, or through the appearance of new transformations 
TABLE I. $\Delta H$ and $\Delta S$ contributions per $\mathrm{CH}_{2}$ group for different hydrocarbon chain systems.

\begin{tabular}{|c|c|c|c|c|}
\hline Series & $\Delta H / R K$ & $\Delta S / R$ & Ref. & Remarks \\
\hline $\begin{array}{l}\text { Thallium(I) } \\
n \text {-alkanoates }\end{array}$ & $170 \pm 10$ & $0.5 \pm 0.1$ & This work & Solid-solid transitions, fusion \\
\hline $\begin{array}{l}\text { Thallium(I) } \\
n \text {-alkanoates }\end{array}$ & $515 \pm 27$ & $1.4 \pm 0.1$ & This work & $\begin{array}{l}\text { Solid-solid transitions, fusion, } \\
\text { clearing, and "gradual enhancement } \\
\text { of the lattice heat capacity" (see text) }\end{array}$ \\
\hline $\begin{array}{l}\text { Lead(II) } \\
n \text {-alkanoates }\end{array}$ & $\begin{array}{l}579.7 \pm 0.1 \\
580\end{array}$ & $\begin{array}{c}1.46 \pm 0.01 \\
1.1\end{array}$ & $\begin{array}{c}32 \\
33,34,35\end{array}$ & Solid-solid, fusion, and clearing \\
\hline $\begin{array}{l}\text { Copper(II) } \\
n \text {-alkanoates }\end{array}$ & 330 & - & 36 & $\begin{array}{l}\text { Solid-solid and only first fusion (not } \\
\text { clearing) }\end{array}$ \\
\hline$n$-alkanes & $\begin{array}{c}487 \\
475 \pm 12\end{array}$ & 1.3 & $\begin{array}{c}37 \\
38,39\end{array}$ & Fusion and solid-solid transitions \\
\hline Polyethylene & 493 & 1.19 & 40,41 & Melting of polyethylene \\
\hline$n$-alkanoic acids & - & 1.25 & 42,43 & Fusion and solid-solid transitions \\
\hline$n$-alkenoic acids & - & $0.45-0.51$ & 44 & \\
\hline $\begin{array}{l}\text { Primary } n \text {-alkyl } \\
\text { amine chlorides }\end{array}$ & - & 1.1 & 45 & $\begin{array}{l}\text { Conformational fusion, fusion, and } \\
\text { clearing }\end{array}$ \\
\hline $\begin{array}{l}\text { Glycidic esters of } \\
n \text {-alkylcarboxylic } \\
\text { acids }\end{array}$ & - & 1.35 & 46 & Fusion \\
\hline Bilayer perovskites* & - & $0.9^{\mathrm{a}}$ & 27 & Solid-solid, fusion, and clearing \\
\hline
\end{tabular}

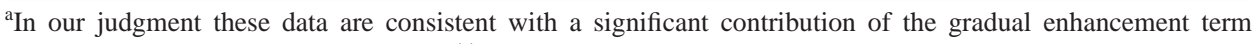
discussed in this work for the thallium(I) series.

associated with the increase of the number of carbons in the chain. In general, both events may occur simultaneously, but for alkali and alkaline earth series the second one occurs more frequently. The thallium(I) $n$-alkanoates series behaves in a more complicated way: the number of transitions increases in the intermediate chain length (a mesophase appears above $n=5$ as well as more solid-to-solid transitions) but the number of transitions decreases with higher $n$. Since the sum of the melting terms $\left(\Delta_{\mathrm{fus}} S+\Delta_{\mathrm{clr}} S\right)$ are nearly constant (varying between $2.15 R$ and $2.60 R$ ), the observed $\Delta_{\text {cry }}^{\text {liq }} S$ increments with $n$ are due to the intercrystalline transitions and to the contribution of the gradual enhancement term (i.e., to processes in which the $n$-alkyl chains participate), whilst the fusion and clearing transitions are related with the energy needed to overcome the electrostatic interactions, producing the corresponding entropy increment. Even more, the approximate constancy of $\left(\Delta_{\text {fus }} S+\Delta_{\text {clr }} S\right) R$ terms points-as was noted earlier-to a similar structure for the solid I phases among all the members of the series studied by us, with the exception of $\mathrm{Tl} 3 \mathrm{C}$ and $\mathrm{T} 14 \mathrm{C} .{ }^{15,18}$ in which ionic interactions predominate due to their very short chains. The same conclusion can be obtained from Lindau et al. data up to $n=17$, from which solid I phase disappears. ${ }^{21}$ Similar to what was found for enthalpy increments, $\Delta_{\text {fus }} S$ strongly increases above $n=17$.

From the slope of our $\Delta_{\text {cry }}^{\text {liq }} S$ data vs $n$ we estimate $\Delta S\left(\mathrm{CH}_{2}\right)=(1.4 \pm 0.1) R$ for this series. This value is slightly

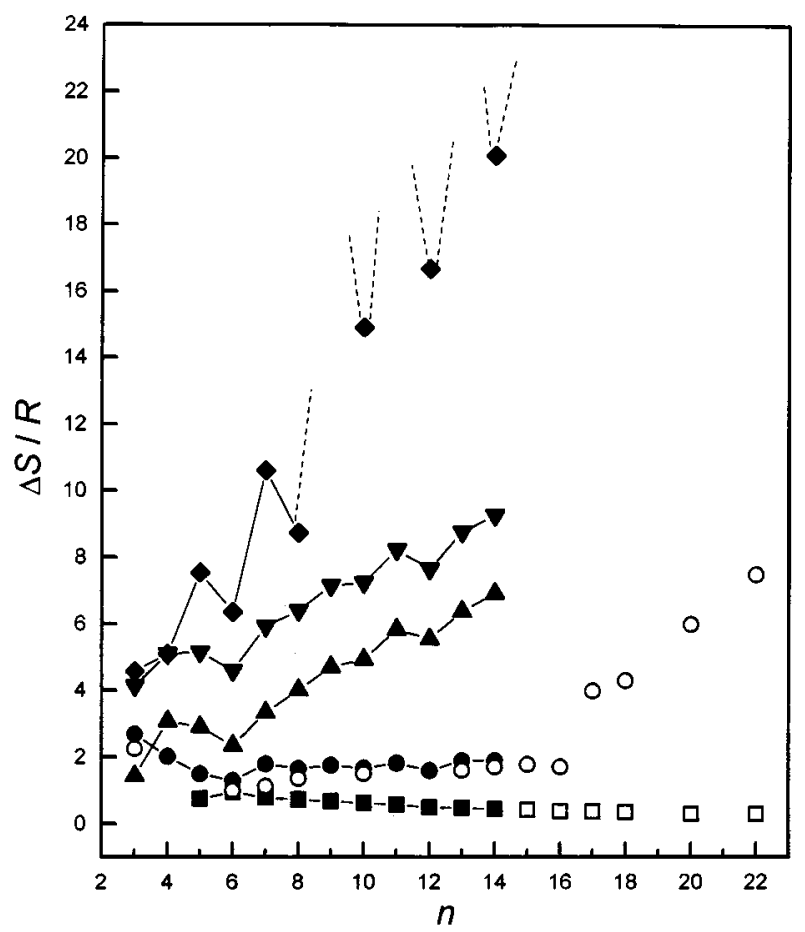

FIG. 8. Entropies of the observed transitions for the thallium(I) $n$-alkanoates versus number of carbon atoms, $n$. Open symbols, data from Refs. 20, 21. $\bullet=\Delta_{\text {cry }}^{\operatorname{lig}} S, \boldsymbol{\Delta}=\Sigma_{i} \Delta_{S S} S_{i}, \boldsymbol{\theta}=\Delta_{\text {fus }} S$, and $\mathbf{\square}=\Delta_{\text {crr }} S, \boldsymbol{\nabla}=\Sigma_{i} \Delta_{S S} S_{i}+\Delta_{\text {fus }} S$ $+\Delta_{\mathrm{clr} S} S$. 
higher than the customary theoretical value $(R \ln 3)$ on the hydrocarbon segments of flexible long chain molecules. ${ }^{37}$ According to this, it may be stated from both enthalpy and entropy points of view that the stepwise melting process is completed when the isotropic liquid phase is reached.

\section{E. Interpretation of the nature of the phase transitions}

Most of the solid-to-solid transitions are associated with crystalline structural changes. The results from FTIR and Raman spectroscopy ${ }^{5}$ showed that for $n \geqslant 7$ a structural change concerning the carboxylate groups takes place at SIII-to-SII transition: the two CO stretching bands in SIII and phases below coalesce into one at this transition temperature. Any structure proposed for SIII and other phases at lower temperatures would take into account this fact. A possibility for this is that the structural entities in the crystal are dimers, similar to those found for aromatic $\beta$-diketonates thallium(I) complexes. ${ }^{47}$ In this structure the coordination of the each oxygen of the same carboxylate group is different, explaining the presence of two $\mathrm{CO}$ stretching bands.

Interpretation of the phase transitions in long-chain compounds may be achieved by resolving their most important enthalpy and/or entropy contributions, introducing reasonable theoretical estimates for each one and determining whether their sum corresponds with the experimental results. This decomposition model has been widely used in macromolecular systems (in particular, for polyethylene) and for membrane models. ${ }^{3,48,49}$ Extension of this analysis-based fundamentally on the ideas of Nagle and Goldstein $-{ }^{41}$ is restricted to the global changes of $\Delta H$ and $\Delta S$ from the crystalline phase stable at low temperatures to the isotropic liquid phase. We will use Tl10C as a model compound in the subsequent development, but the reasoning and the conclusions should be valid for the other members of the homologous series as well.

The variation of the global enthalpy for fusion $\Delta_{\text {cry }}^{\mathrm{liq}} H$ can be expressed as the sum of various contributions:

$$
\Delta_{\text {cry }}^{\text {liq }} H=\left(\Delta_{\text {conf }} U+\Delta_{\text {vdW }} U+\Delta_{\text {ion }} U\right)+p \Delta V .
$$

Here, $\Delta_{\text {conf }} U$ and $\Delta_{\mathrm{vdW}} U$ are the energy increments in the conformational disorder (rotational isomerism trans-gauche) and in the variation of the cohesive interactions of van der Waals, respectively. $\Delta_{\text {ion }} U$ includes the other energy terms (such as changes in the electrostatic interactions). The term $p \Delta V$ is insignificant compared to other contributions: for example, $\Delta_{\text {cry }}^{\text {liq }} V(\mathrm{Na} 4 \mathrm{C})^{1} \sim 25 \mathrm{~cm}^{3} \cdot \mathrm{mol}^{-1}$ and $\Delta_{\text {cry }}^{\text {liq }} V(\mathrm{~Pb} 10 \mathrm{C})^{36} \sim 50 \mathrm{~cm}^{3} \cdot \mathrm{mol}^{-1} ; \quad$ if $p=1 \mathrm{~atm}, \quad p \Delta V$ $=2.5-5 \mathrm{~J} \cdot \mathrm{mol}^{-1}$ (approximately $0.5 R \mathrm{~K}$ ).

To determine $\Delta_{\text {conf }} U$ it is necessary to know the number of gauche conformations for hydrocarbon chains that are formed in the fusion process. The only published work on the dynamic properties of thallium(I) $n$-alkanoates is a NMR study of ${ }^{1} \mathrm{H}$ and ${ }^{205} \mathrm{Tl}$ for the members of the series $\mathrm{Tl} 12 \mathrm{C}$, $\mathrm{Tl} 14 \mathrm{C}$, and $\mathrm{Tl} 22 \mathrm{C} .^{50}$ Two or three isomerizations transgauche per chain occur in the Crystal Phase II of the T112C, $\mathrm{Tl} 14 \mathrm{C}$, and more are involved in the Crystal Phase I. According to this work, the stable phases at ambient and lower temperatures would be characterized by aliphatic chains with all-trans conformations in Tl22C. For this compound, the average order parameter observed for the aligned group in the temperature interval of existence of the mesophase is 0.17 (explicable upon assuming the existence of 5 to 7 transgauche defects in each chain). ${ }^{50}$ Combining the above information with the energy difference of $250 R \mathrm{~K}$ between the trans and gauche conformers, ${ }^{41}$ they obtain $\Delta_{\text {conf }} U$ $\sim 750 R \mathrm{~K}$, for the T110C. Since the experimental value obtained for thallium(I) $n$-decanoate is $\Delta_{\text {cry }}^{\text {liq }} H=4871 R \mathrm{~K}$ (cf. Fig. 2) it is clear that the increments for the intramolecular energy changes $\Delta_{\text {conf }} U$ are insufficient to account for the global enthalpy of the fusion process.

A second source of enthalpy increment is associated with the volume increment in the transitions between the stable crystal phase at low temperatures to the isotropic liquid phase. On the average, each hydrocarbon chain is found in this final liquid state further separated from its neighbors than in the crystalline state. For this to occur, it is necessary to apply an energy, $\Delta_{\mathrm{vdW}} U$, equal to the work against the intramolecular interactions that keep the system in a crystalline phase. These interactions are, basically, van der Waals attractive forces. Nagle and Goldstein ${ }^{41}$ estimated them applying the theoretical treatment of Salem ${ }^{51}$ to the experimental data of the cohesive energy density in polyethylene, and proposed the value $\Delta_{\mathrm{vdW}} U=360 R \mathrm{~K}$, per $\mathrm{CH}_{2}$, without taking into account the repulsive terms. If these are included, $\Delta_{\mathrm{vdW}} U$ is reduced to $315 R \mathrm{~K}$. Based on the value of $\Delta_{\mathrm{vap}} H$, Bunn ${ }^{48}$ obtained $340 R \mathrm{~K}$ for $\Delta_{\mathrm{vdW}} U$, per $\mathrm{CH}_{2}$. Consequently, an adequate $\Delta_{\mathrm{vdW}} U$ value for Tl10C would be comprized between (2800 and 3100) $R \mathrm{~K}$. On the other hand, in Fig. 7 it is observed that $\Delta_{\text {fus }} H$ remains constant above $n=5$, independent of the number of carbon atoms in the alkyl chain. Therefore, $\Delta_{\text {fus }} H$ can be attributed to the melting of the ionic layers. Even when a small odd-even effect is observed in this transition, an average value of $700 R \mathrm{~K}$ can be estimated for $\Delta_{\text {fus }} H$ (or $\Delta_{\text {ion }} U$ ). Hence, $\Delta_{\text {conf }} U+\Delta_{\text {vdW }} U$ $+\Delta_{\text {ion }} U$ would be a value between $4300 R \mathrm{~K}$ and $4500 R \mathrm{~K}$, which is near the experimental value $4871 R \mathrm{~K}$. The difference between them could be due to a higher number of gauche defects in the conformational contribution.

In summary, the total enthalpy absorbed by the thallium(I) $n$-alkanoates, in passing from the solid phase stable at low temperatures to the isotropic liquid can be decomposed into three terms: the variation of the electrostatic interactions $\Delta_{\text {ion }} U$, the progressive conformational intramolecular disorder $\left(\Delta_{\operatorname{conf}} U\right)$, and the variation of the van der Waals interactions between the hydrocarbon chains $\left(\Delta_{\mathrm{vdW}} U\right)$. The first term dominates, obviously, for shortchain homologous series. The other two become predominant with the length increase of the hydrocarbon chain.

The statistical thermodynamic basis used for the enthalpy calculations is less consistent when applied to the entropy changes because the different contributions are not independent each other. Nonetheless, a similar considerations can be developed using the Nagle and Goldstein ${ }^{41}$ terminology and the proposed values for polyethylene:

$$
\Delta_{\text {cry }}^{\operatorname{liq}} S=\Delta_{\text {conf }} S+\Delta_{x} S+\Delta_{\mathrm{v}} S+\Delta_{0} S,
$$

where $\Delta_{\text {conf }} S(\sim 0.85 R)$ is the entropy increments due to the 
conformational changes, $\Delta_{x} S(\sim-0.36 R)$ the excluded volume term, $\Delta_{\mathrm{V}} S(\sim 0.50 R$ to $0.88 R)$ the contribution due to the difference in volume between the liquid and the solid, and $\Delta_{0} S(\sim 0.2 R$ to $-0.18 R)$ includes all the other entropy sources. These values give an entropy contribution to the melting process of $0.81 R$ to $1.57 R$ per $\mathrm{CH}_{2}$ group.

The $\Delta_{0} S$ term for the thallium(I) $n$-alkanoate series can be estimated experimentally from the $\Delta_{\text {fus }} S$, similarly to the $\Delta_{\text {ion }} U$ evaluation, as a constant value of $1.68 R$. Hence, $\Delta_{\text {cry }}^{\text {liq }} S$ would be comprised between $8.97 R$ and $15.81 R$ for Tl10C. The experimental value for thallium(I) $n$-decanoate is $14.91 R$ (cf. Fig. 8), which is inside the estimated range, near the upper limit.

On the basis of $\mathrm{x}$-ray diffraction ${ }^{49}$ and viscosity ${ }^{52}$ measurements on alkali or alkaline earth $n$-alkanoates, it has been suggested that a certain structural order persists in the isotropic liquid phase to temperatures slightly superior to those of clearing. This anisotropy would be due to the presence of molecular aggregates. Indeed the existence of two "near" mesophases has been suggested in some amphiphilic compounds comprising a hydrocarbon chain and an ionic extremity. ${ }^{36,53,54}$ We found no experimental evidence by dsc of a behavior like this for the thallium(I) series. Moreover, the agreement between the experimental and estimated $\Delta_{\text {cry }}^{\text {liq }} S$ values suggests that the melting process is finished and no other entropy source may be expected above the clearing point.

\section{ACKNOWLEDGMENT}

Partial support of this research by the DGICYT of the Spanish Ministerio de Educación y Ciencia (Project No. PB93-0432) is gratefully acknowledged.

\section{APPENDIX: PHASE TEXTURES BY POLARIZED- LIGHT MICROSCOPY}

The optical observations of the different phases textures for the thallium(I) $n$-alkanoates were made with a JenaZeiss (Jenalab pol-30-GO527 model) polarized light microscope, provided with a Mettler model FP80+FP82 hot stage to control the temperature. A source of white light was used to observe the samples (placed on a borosilicate glass slide with a cover previously cleaned with acetone) between the polarizers. The best way to observe the liquid crystal texture was to heat the samples to the isotropic liquid and rapidly cool it into the mesophase. For all the samples of the thallium(I) $n$-alkanoates studied - from the Tl5C up to $\mathrm{Tl} 14 \mathrm{C}-\mathrm{a}$ very clear conic-focal texture mesophase is observed when cooling from the isotropic liquid phase. The mesophase appears with formation of the typical "bâtonnets" characteristic of the Smectic-A-type. Such "bâtonnets" finally coalesce, producing the fan shape.

All the observations made confirmed the identification of the mesophase as a "Smectic-A-type" or "neat" phase. Their identification is in agreement with the results of other researchers on other alkaline carboxylates ${ }^{55}$ and on the same series of thallium(I) $n$-alkanoates. ${ }^{56}$

Figure 9 shows average domain sizes versus both the molecular length and number of carbons. In Fig. 9 it is clear

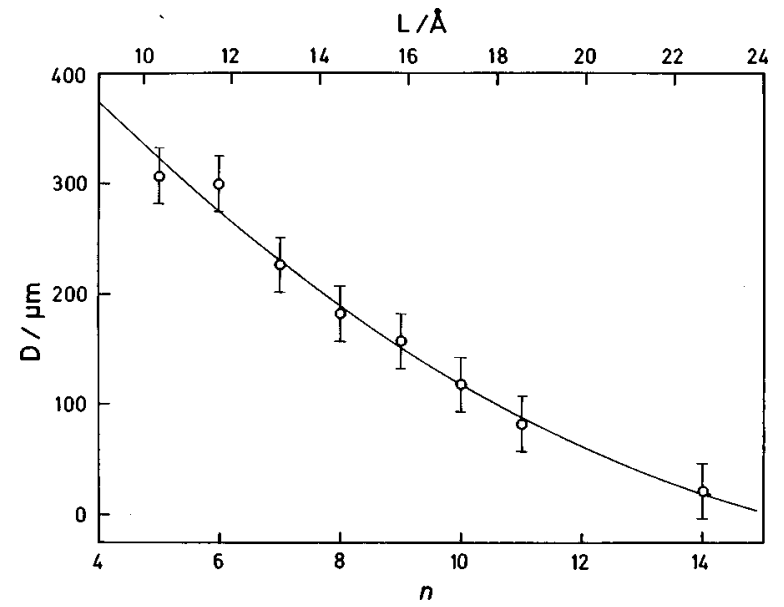

FIG. 9. Domain sizes $(D)$ of the mesophases textures for thallium(I) $n$-alkanoates in terms of the total number of carbon atoms $(n)$ and an approximate molecular length $(L)$.

that, as expected, the longer the alkyl chain in the salt, the smaller the size of the domain. Values for $\mathrm{Tl} 12 \mathrm{C}$ and $\mathrm{Tl} 13 \mathrm{C}$ are absent from this figure because it was not possible to get the nonhomeotropic texture for these two samples.

In all the salts, the interference colors of the texture of mesophases vary, according to the Newton scale, when the temperature increases, from the rather pale yellow at low temperatures to a reddish orange at high temperatures, which corresponds to about one-third of the first order of the cited scale. ${ }^{57}$ For the thallium(I) $n$-decanoate, the variation was greater, from yellow at $135^{\circ} \mathrm{C}$ to greenish blue near the "clearing point": this represents more than half of an interference order in Newton's color scale.

${ }^{1}$ J. J. Duruz, H. J. Michels, and A. R. Ubbelohde, Proc. R. Soc. London, Ser. A 322, 281 (1971).

${ }^{2}$ T. A. Mirnaya, V. D. Prisyazhny, and V. A. Shcherbakov, Russ. Chem. Rev. 58, 821 (1989).

${ }^{3}$ J. F. Nagle, J. Chem. Phys. 58, 252 (1973).

${ }^{4}$ J. F. Nagle, Annu. Rev. Phys. Chem. 31, 157 (1981).

${ }^{5}$ M. V. Garcia, M. I. Redondo, F. L. López de la Fuente, J. A. R. Cheda, E. F. Westrum, Jr., and F. Fernández-Martín, Appl. Spectrosc. 48, 338 (1994).

${ }^{6}$ F. Fernández-Martín, F. L. López de la Fuente, and J. A. R. Cheda, Thermochim. Acta 73, 109 (1984).

${ }^{7}$ J. Boerio-Goates, F. L. López de la Fuente, J. A. R. Cheda, and E. F. Westrum, Jr., J. Chem. Thermodyn. 17, 401 (1985).

${ }^{8}$ S. P. Ngeyi, F. L. López de la Fuente, J. A. R. Cheda, F. FernándezMartín, and E. F. Westrum, Jr., J. Chem. Thermodyn. 17, 409 (1985).

${ }^{9}$ S. P. Ngeyi, E. F. Westrum, Jr., F. L. López de la Fuente, J. A. R. Cheda, and F. Fernández-Martín, J. Chem. Thermodyn. 19, 327 (1987).

${ }^{10}$ F. L. López de la Fuente, E. F. Westrum, Jr., J. A. R. Cheda, and F. Fernández-Martín, J. Chem. Thermodyn. 19, 1261 (1987).

${ }^{11}$ F. L. López de la Fuente, J. A. R. Cheda, F. Fernández-Martín, and E. F. Westrum, Jr., J. Chem. Thermodyn. 20, 1137 (1988).

${ }^{12}$ A. R. Labban, F. L. López de la Fuente, J. A. R. Cheda, E. F. Westrum, Jr., and F. Fernández-Martín, J. Chem. Thermodyn. 21, 375 (1989).

${ }^{13}$ M. V. Roux, C. Turrión, F. Fernández-Martín, F. L. López de la Fuente, and J. A. R. Cheda, Thermochim. Acta 139, 139 (1989).

${ }^{14}$ F. Fernández-Martín, F. L. López de la Fuente, J. A. R. Cheda, and E. F. Westrum, Jr., XXI Reunión Bienal de la R. S. Española de Quimica. 1986. Santiago de Compostela (Spain). Resúmenes de Comunicaciones, p. 635.

${ }^{15}$ J. A. R. Cheda, F. Fernández-Martín, R. J. Burns, and E. F. Westrum, Jr., J. Chem. Thermodyn. 26, 829 (1994).

${ }^{16}$ F. L. López de la Fuente, "Propiedades Termofísicas y Transiciones de 
Fase de n-Alcanoatos de Talio(I), " Ph.D. thesis, Universidad Complutense, Madrid, Spain, 1989, Section IV.

${ }^{17}$ J. A. R. Cheda, P. Ungarelli, F. L. López de la Fuente, F. FernándezMartín, Y. Xu, W. L. IJdo, and E. F. Westrum, Jr., Thermochim. Acta 266, 163 (1995).

${ }^{18}$ F. Fernández-Martín, J. A. R. Cheda, L. L. Jones, C. C. Lin, and E. F. Westrum, Jr., J. Chem. Thermodyn. 26, 925 (1994).

${ }^{19}$ B. Wunderlich, M. Möller, J. Grebowicz, and H. Baur, in Conformational Motion and Disorder in Low and High Molecular Mass Crystals, edited by H. Höcker (Springer-Verlag, New York, 1988), pp. 1-6.

${ }^{20}$ J. Lindau, S. Diele, H. Kruger, and H. D. Dörfler, Z. Phys. Chem. (Leipzig) 262, 775 (1981)

${ }^{21}$ J. Lindau, H. J. König, and H. D. Dörfler, Colloid Polym. Sci. 261, 236 (1983).

${ }^{22}$ R. Krombach and G. M. Schneider, J. Chem. Thermodyn. 25, 445 (1993).

${ }^{23}$ W. B. Person and G. C. Pimentel, J. Am. Chem. Soc. 75, 532 (1953).

${ }^{24}$ M. G. Broadhurst, J. Res. Natl. Bur. Stand., Sect. A 67, 233 (1963).

${ }^{25}$ P. Sellers, G. Stridh, and S. Sunner, J. Chem. Eng. Data 23, 250 (1978).

${ }^{26}$ S. Sunner and C. A. Wulff, J. Chem. Thermodyn. 12, 505 (1980).

${ }^{27}$ M. A. White, J. Chem. Phys. 81, 6100 (1984).

${ }^{28}$ S. P. Ngeyi, E. F. Westrum, Jr., and P. Franzosini, J. Chem. Thermodyn. 18, 609 (1986)

${ }^{29}$ Y. Jin and B. Wunderlich, J. Phys. Chem. 95, 9000 (1991).

${ }^{30}$ K. S. Pitzer, J. Chem. Phys. 8, 711 (1940), Chem. Rev. 27, 39 (1940).

${ }^{31}$ G. J. Janz, Thermodynamical Properties of Organic Compounds (Academic, New York, 1967), Chap. 3, pp. 35.

${ }^{32}$ A. Sánchez Arenas, M. V. García, M. I. Redondo, J. A. R. Cheda, M. V. Roux, and C. Turrion, Liq. Cryst. 18, 431 (1995).

${ }^{33}$ H. A. Ellis, Mol. Cryst. Liq. Cryst. 139, 281 (1986).

${ }^{34}$ A. M. Amorim da Costa, H. D. Burrows, C. F. C. G. Geraldes, J. J. C. Teixeira-Dias, C. G. Bazuin, D. Guillon, A. Skoulios, E. Blackmore, G. J. T. Tiddy, and D. L. Turner, Liq. Cryst. 1, 215 (1986).

${ }^{35}$ C. G. Bazuin, D. Guillon, A. Skoulios, A. M. Amorim da Costa, H. D. Burrows, C. F. G. C. Geraldes, J. J. C. Teixeira-Dias, E. Blackmore, and G. J. T. Tiddy, Liq. Cryst. 3, 1655 (1988).

${ }^{36}$ H. Abied, D. Guillon, A. Skoulios, P. Weber, A. M. Giroud-Godquin, and J. C. Marchon, Liq. Cryst. 2, 269 (1987).

${ }^{37}$ R. C. Weast, Ed. Handbook of Chemistry and Physics, 64th ed. (CRC Press, Boca Raton, 1983).
${ }^{38}$ P. Espeau, L. Roblès, D. Mondieig, Y. Haget, M. A. Cuevas-Diarte, and H. A. J. Oonk, J. Chim. Phys. 93, 1217 (1996).

${ }^{39}$ A. Bondi, Chem. Rev. 67, 565 (1967); Physical Properties of Molecular Crystal, Liquids and Glasses (Wiley, New York, 1968), p. 159.

${ }^{40}$ B. Wunderlich and G. Czornj, J. Polym. Sci., Polym. Phys. Ed. 15, 1905 (1977).

${ }^{41}$ J. F. Nagle and M. Goldstein, Macromolecules 18, 2643 (1985).

${ }^{42}$ R. C. F. Schaake, J. C. van Miltenburg, and C. G. de Kruif, J. Chem. Thermodyn. 14, 763 (1982).

${ }^{43}$ R. C. F. Schaake, J. C. van Miltenburg, and C. G. de Kruif, J. Chem. Thermodyn. 14, 771 (1982).

${ }^{44}$ M. Kobayashi, F. Kaneko, K. Sato, and M. Suzuki, J. Phys. Chem. 90, 6371 (1986)

${ }^{45}$ V. Busico, P. Cernichiaro, P. Corradini, and M. Vacatello, J. Phys. Chem. 87, 1631 (1983)

${ }^{46}$ F. Fernández-Martín, J. Am. Oil Chem. Soc. 50, 170 (1973).

${ }^{47}$ J. Barberá, C. Cativiela, J. L. Serrano, and M. M. Zurbano, Adv. Mater. 3, 602 (1991).

${ }^{48}$ C. W. Bunn, J. Polym. Sci. 16, 323 (1955).

${ }^{49}$ J. J. Duruz and A. R. Ubbelohde, Proc. R. Soc. London, Ser. A 330, 1 (1972).

${ }^{50}$ G. Klose, F. Volke, M. Hentschel, and A. Mops, Mol. Cryst. Liq. Cryst. 90, 245 (1983).

${ }^{51}$ L. Salem, J. Chem. Phys. 37, 2100 (1962).

${ }^{52}$ U. J. Ekpe and S. J. Sime, J. Chem. Soc., Faraday Trans. 1 72, 1144 (1976).

${ }^{53}$ V. Busico, A. Ferraro, and M. Vacatello, Mol. Cryst. Liq. Cryst. 128, 243 (1985).

${ }^{54}$ V. Busico, P. Corradini, G. Guerra, and P. Severino, Gazz. Chim. Ital. 115, 17 (1985).

${ }^{55}$ J. Bonekamp and B. Jonas Hegemann, Mol. Cryst. Liq. Cryst. 87, 13 (1982).

${ }^{56}$ E. Baum, D. Demus, and H. Sackmann, Wiss. Z. Univ. Halle 19, 37 (1970).

${ }^{57}$ M. Françon, "Progress in Microscopy," in Modern Trends in Biological Sciences, edited by P. Alexander and Z. M. Bacq (Pergamon, New York, 1961), p. 185. 